\title{
Case Study on the Creation of Class Corner Environment in Kindergartens
}

\author{
Guimei Gao \\ School of Pre-school Education and Special Education \\ Kunming University \\ Kunming, 650214, China
}

\author{
Lina She \\ Department of Scientific Research \\ Kunming University \\ Kunming, 650214, China
}

\author{
Lingling Zhu \\ Tengchong Tengyue kindergarten \\ Tengchong, Yunnan, China
}

\begin{abstract}
Corner activities have various forms and rich contents, which have far-reaching significance for children's education and development. The creation of corner environment directly affects the quality and effect of corner activities. In this paper, a case study of a large class in $\mathrm{Y}$ kindergarten of a municipal kindergarten is carried out. The results show that the corner space layout of the large class in $Y$ kindergarten is scientific and reasonable, the concept is clear, the types are diverse, and the materials are abundant to meet the needs of children's activities. There are also some problems, such as the single concept of teachers, the lack of innovation, the long working intensity, the difficulty of concentrating energy, the lag of teaching and research in the corner of the kindergarten, and so on. Some countermeasures and suggestions are put forward from the aspects of the professional growth of teachers and the optimization of the management of kindergartens.
\end{abstract}

Keywords-kindergarten; class corner; environment creation; case study

\section{INTRODUCTION}

Area corner activities are also called activity area activities and regional activities. Feng Xiaoxia defines corner activities as activities for educators based on activities materials and types of activities that children are interested in, dividing the space of the activity room into different areas so that they can actively choose the activity areas, in which they can learn and develop by fully interacting with materials, environment and peers. [1] Huoliyan believes that the educator divides the activity space according to the characteristics and preferences of the children... As a form of education, this activity promotes the healthy development of personality through the interaction of materials, environment and peers.[2] Environmental psychology holds that the environment is the condition of human existence, and only in the environment can human realize the development of life activities. [3] As a teacher, it is

1. This paper is one of the phased achievements of the guiding project of the Scientific Research Fund of Yunnan Education Department in 2016, "Research on the Creation and Application of Kindergarten Educational Environment" (No. 2016ZDX099).

2. This paper is one of the phased achievements of the Research Institute of Yunnan Provincial Department of Education in 2018, "Research on the Characteristics of Industry-University-Research Cooperation of Local Undergraduate Universities in Yunnan Province from the Perspective of Patent” (No. 2018JS387). necessary to create an effective organizational corner environment to guide children to become active people in this environment, so that children can develop psychological experience and construct personality quality in their interaction with the material world and other people.

Based on this, this study takes three big classes in $\mathrm{Y}$ kindergarten of Municipal Kindergarten as the research object, and combs the current situation of the creation of large class corner activity environment by using the methods of literature, observation and interview.

\section{The PRESENT Situation OF THE ESTABLISHMENT OF CORNER ENVIRONMENT IN LARGE CLASSES OF KINDERGARTENS}

The Ministry of Education's Guidelines for the Development of Children Aged 3-6 pointed out that "Environment is an important educational resource, which should be created and utilized to effectively promote the development of young children." [4] Through observation and interview, this paper investigates and analyses the current situation of corner environment creation in $\mathrm{Y}$ kindergarten classes, including the spatial layout of the corner, the types of corner, material delivery and teacher's guidance observation.

\section{A. The layout of the class corner space is scientific and} reasonable, and the concept is clear

The corner divides the class activity room into several games that children choose independently. The division of district corners is closely related to indoor area, layout and class size. "Reasonable division of regional space plays a positive role in children's active learning.[5]" Based on this, this study designed a class spatial layout scoring table for research, as follows (Table I):

TABLE I. The SPATIAL LAyout OF THE Classes

\begin{tabular}{|c|c|c|c|}
\hline Project & $\begin{array}{c}\text { Freshman } \\
\text { class }\end{array}$ & $\begin{array}{c}\text { Class } \\
\text { two }\end{array}$ & $\begin{array}{c}\text { Class } \\
\text { three }\end{array}$ \\
\hline Space design concept & 2.67 & 3 & 2.67 \\
\hline Spatial segmentation & 2.67 & 2.67 & 2 \\
\hline
\end{tabular}


Cont. to TABLE I.

\begin{tabular}{|c|c|c|c|}
\hline $\begin{array}{c}\text { Conduct activities tailored to local } \\
\text { conditions }\end{array}$ & 2 & 1 & 1 \\
\hline $\begin{array}{c}\text { Grasp the key points of Spatial } \\
\text { planning }\end{array}$ & 3 & 3 & 2.67 \\
\hline Total score & 10.34 & 9.67 & 8.34 \\
\hline
\end{tabular}

As can be seen from the table above, the spatial design concept of sample classes is generally higher than the general level, with scores above 2. Among them, class two scored the highest 3 points, reaching a good level. The design of space should be from the perspective of children, putting children's interests and needs in the first place. The small area and large class size of the large class activity room in the park have brought difficulties to the development of district corner activities, and have further tested teachers' rational arrangement and ingenious design of district corner space.

\section{B. Various types of corner settings}

As an important supplement to Kindergarten Collective Education activities, colorful District corner activities are an important platform for children's development. According to the observation records of the park, it is found that the types of corner in each class are set as follows:

TABLE II. SETting UP OF CORNER TyPes IN THREE ClAsSES

\begin{tabular}{|c|c|c|}
\hline Freshman class & Class two & Class three \\
\hline Performance area & Performance area & Art area \\
\hline Construction area & Construction area & Reading area \\
\hline Puzzle area & Puzzle area & Puzzle area \\
\hline Art area & Art area & Science district \\
\hline Reading area & Reading area & Construction area \\
\hline & & Music area \\
\hline
\end{tabular}

The setting of sample class corner basically meets the needs of children's activities objectively. On the one hand, the choice of district angle can be considered in terms of type, quantity and space; on the other hand, teachers can set up according to the characteristics of children's age, interests and needs, and existing resources.

\section{The corner activities are rich in materials to meet the needs of children's activities}

Dong Xuhua believes that the materials for corner activities "mainly refer to the objects that teachers put into the corner of the activity area for children to operate, test and explore freely." [6] According to Professor Dong Xuhua's theoretical framework, this paper mainly analyzes the sources of materials, materials delivery and materials management. The results are as follows (Table III):

TABLE III. MATERIAL SITUATION OF THREE CLASSES

\begin{tabular}{|c|c|c|c|}
\hline Project & Freshman class & Class two & Class three \\
\hline $\begin{array}{c}\text { Source of } \\
\text { materials }\end{array}$ & 2.3 & 2.3 & 2 \\
\hline $\begin{array}{c}\text { Material } \\
\text { delivery }\end{array}$ & 2.67 & 3 & 2.3 \\
\hline $\begin{array}{c}\text { Material } \\
\text { management }\end{array}$ & 3.12 & 3.3 & 3 \\
\hline Total score & 8.09 & 8.6 & 7.3 \\
\hline
\end{tabular}

As shown in the table above, in terms of material sources, freshmen and class two exceed the general level with a score of
2.3, while class three only reach the general level with a score of 2. Based on the investigation, we can further analyze the situation. The corner materials of sample classes can reflect specific educational intentions, conform to the level of children's ability and arouse children's interest in activities. From the perspective of material delivery, Class Two is at a good level of 3 points, freshmen is 2.67 points, Class Three is above the general level of 2.3 points, between the general level and the good level. The number of freshman and class two can meet the needs of children in the whole class at the same time. Among them, the number of the second class is slightly more, while the number of the class three is lower than the first two classes. At the same time, in material management, the sample class material management has fixed container storage and placement position, material access and use have clear requirements for operability, easy to manage.

\section{ANALYSIS ON THE PROBLEMS AND CAUSES OF THE CREATION OF THE ENVIRONMENT IN THE KINDERGARTEN AREA}

\section{A. The concept of creating teachers' corner environment is single and the innovation is insufficient}

Through observation and interviews, it is found that there is no clear goal for teachers in the concept of corner environment creation. They just set up regular corner according to construction, art, intelligence and so on. They complete tasks on time, not to mention the individual level differences of goals While some teachers can put forward new ideas, they don't practice them. They just stay at the level of "think about it". The reason is that kindergartens and teachers do not pay enough attention to the concept is not correct, leading to weak support for the creation of corner environment. The reasons are as follows: First, teachers are under great pressure. Kindergartens require teachers to hand in their results and evaluate them within the prescribed time. Teachers have to work overtime to catch up with the progress. Secondly, the teachers themselves are weak in their attitude towards creation and lack the ability to apply theory to practice because they do not grasp the characteristics of children's age and the existing cognitive level. Thirdly, teachers' ability to create corner environment is insufficient, and it is difficult to break through and strive for innovation.

\section{B. Teachers work hard for a long time, and it's hard for them to concentrate}

Firstly, in terms of spatial layout, for example, in the case of large building blocks area, children have disliked it, can't explore new ways of playing, but like the material-rich art area. But the teachers did not adjust to this situation. The reason is that teachers are not flexible enough, lack of meticulous and keen observation, and can't solve children's puzzles in the process of activities in a timely manner. The reason for neglecting the use of public space is that teachers believe that the corner of classroom activity room can meet the needs of children's activities, and there is no need to expand the corner to the outside. And the corridor is not very spacious. Every time we carry out activities, we have to put the materials in place and tidy them up. It's a waste of time and hard work for 
teachers. The shared game area involves all classes participating in the game and management together. It is not in the scope of consideration that conflicts easily arise because of different ideas and concepts. Each District corner is relatively closed and lacks cooperation and communication. The main reason is that teachers are afraid of trouble, so the regulations are easy to manage.

Secondly, there is the problem of idle and non-renewal in the corner types. Through observation, we find that the main reasons are as follows: first, teachers have limited time and energy. After completing the task of creating corner environment in kindergartens, they are not willing to update and adjust, or even leave the corner area without putting materials into use, just to cope with the inspection; secondly, teachers lack innovative ability and are confined to conventional areas.

Thirdly, in terms of material delivery, the sources of materials are single, and the participation of children in material delivery is low. The reason is that teachers should first ensure that they provide enough activity materials for children when putting materials into use. Teachers' production, children's and parents' production are time-consuming and laborious. The most convenient way is to buy and put them into use by themselves.

\section{The corner of the school is lagging behind, and it has not played a leading role.}

Through observation and analysis of interview records, it is found that kindergartens have no communication and Discussion on the creation of district corner environment and the development of district corner activities. The general problems in District corner activities, such as spatial layout, types of district corner, material delivery and activity guidance, can't be studied in time. Solutions or suggestions are put forward to solve these problems, which also restricts the development of teachers and fails to improve their organizational ability of district corner activities. On the other hand, kindergarten teachers do not know enough about the creation of corner environment, and it is difficult to grasp the creation of corner environment. There is a lack of leadership and systematic training in kindergartens.

\section{COUNTERMEASURES AND SUGGESTIONS ON THE ESTABLISHMENT OF CORNER ENVIRONMENT IN LARGE CLASSES OF KINDERGARTENS}

\section{A. Strengthening teachers' professional training and renewing the idea of creating district corner}

The training of teachers' ability to create district environment should be strengthened. As an organizer of the activities, before the activities are carried out, we must make reasonable and correct plans; accurately and clearly grasp each child's psychological status and development needs. Every child's family situation and the growing environment are uneven. It requires a lot of preparations before the activities are carried out. Therefore, a good plan is an important prerequisite for the success of the activities. Secondly, clear objectives, on this basis, combined with the age characteristics of children at all stages and the ability level of children in this class, formulate stage goals. Finally, teachers themselves should have the consciousness and ability of self-education, "establish the concept of lifelong learning, form the consciousness of selfeducation, and understand the necessity of self-education; then define the social expectation and role orientation of the profession, consciously self-reflection, and self-awareness and self-supervision in various forms. "[7]

Teachers' ability to observe and guide District corner activities should be improved. On the one hand, targeted observation is the prerequisite for teachers to guide children's games. Observation can help teachers understand the interests and needs of children's games, children's development level and problems in children's games so that teachers can guide children's games. In the process of guidance, teachers must pay attention to the following two problems: first, careful observation, truly teaching with emotion, teaching with the heart; second, observation with purpose and randomness.

\section{B. Optimizing teachers' working environment and promoting teachers' working efficiency}

In the creation of district corner activities in reality, some teachers often catch up with the progress in order to complete the task, resulting in the weakening of the concept of creation, and even serious career slack. Looking closely at the kindergarten teachers around us, it is not difficult to find that many teachers are often depressed, and some even develop into physical diseases, often hear them complain about their dissatisfaction with their work. Sometimes this emotion is even brought into the teaching process, which is a serious irresponsible behavior for children. In view of these situations, kindergartens need to optimize the working environment of teachers and improve their working efficiency. We can start from these aspects:

On the one hand, we should guide teachers to understand their professions reasonably. Managers should vigorously stimulate each teacher's sense of honor and responsibility, carry out various activities to commend excellent teachers, so that teachers can feel the great value of their own existence, and understand that the healthy growth of young children is a responsibility for each family.

At the same time, the humanized management atmosphere should be constructed. As a manager, it is an important guarantee to truly communicate with every teacher and heart, to care about their vital interests, to understand the needs of every teacher, to coordinate and rationally arrange work, to do a good job of job distribution plan, and to avoid excessive pressure on teachers. The appropriate workload is an important guarantee for the completion of teaching work. At the same time, we should clearly divide the work into different duties, advocate healthy work and arrange working hours reasonably.

\section{Strengthening the leadership of kindergarten teaching and research, highlighting the creation of district corner environment and regularizing and institutionalize District corner teaching and research}

There is no fixed content in corner activities. It is quite difficult for teachers to design new content and make new 
materials from time to time. In order to reduce the difficulty, it is advisable for the garden to discover and promote good materials and contents in the activity areas of each class in time, and to organize regular observation and discussion. Those toys which have been proved to be popular and scientific and durable by children can be saved in the form of physical objects, photographs, words, etc. Those excellent activity cases can be collected and compiled once a semester or every school year to form kindergarten-based materials for teachers to learn from.

The kindergarten teaching and development system should form an atmosphere in which the head of the kindergarten and the head of the teaching kindergarten take the lead and the teachers respond positively. Leaders adhere to the concept of people-oriented; organize teachers to carry out teaching research. Teachers seriously study, study, analyze and gather the wisdom of the public to put forward countermeasures and suggestions. This top-down corner teaching and research activities should be routine and institutionalized. Teachers respond positively. First of all, they change their concepts from "I have to learn" to "I want to learn", carry out reflective practice, improve teachers' reflective ability and professional level, and form a bottom-up research atmosphere. The primary task of teaching and research in District corners is to solve the common problems existing in front-line teachers. Secondly, aiming at individual problems, teachers should solve their own puzzles and help each other to stimulate their internal motivation and promote their own development. Teachers are the raisers of problems and the researchers of their own practice.

\section{CONCLUSION}

This paper mainly uses literature research, observation and interview to investigate $\mathrm{Y}$ kindergarten in Kunming. It is found that there are some problems in the establishment of kindergarten corner environment, such as spatial layout, types of corner, material delivery and teachers' observation and guidance. The reasons that influence the creation of corner environment in kindergartens are analyzed from three aspects: the idea of creating corner environment in kindergartens, the intensity of teachers' work and the teaching and research in kindergartens. Suggestions for improvement are put forward from three aspects: strengthening teachers' professional training, optimizing teachers' working environment and strengthening kindergarten teaching and research guidance. Generally speaking, there are still many shortcomings in this study and the research methods and sample selection need to be further improved. The research on the creation of kindergarten corner environment can be continued and further improved in the future work.

\section{REFERENCES}

[1] Feng Xiaoxia. Kindergarten Course [M]. Beijing: Beijing Normal University Press, 2000:259.

[2] Holliyan, Sun Dongmei. Kindergarten Curriculum Development and Teacher Professional Development: A Comparative Study Perspective [M]. Beijing: Educational Science Press, 2006:126.

[3] Wang Shanshan. New advances in environmental psychology abroad [J]. Department of Social Psychology: 2008 (5), 434-438.

[4] Li Jimei, Feng Xiaoxia. Interpretation of the Guide to Learning and Development for Children Aged 3-6 [M]. Beijing: People's Education Press, 2013.

[5] Lin Yuhui. Regional Environment Creation Strategy for Promoting Active Learning of Children in Small Classes: Learning, Exploration and Practice Based on "Heisengao" District Corner Model [J]. Fujian Basic Education Research. 2018 (06): 130-132.

[6] Dong Xuhua, Han Glacier, et al. Small Regional University QuestionGuidance on Regional Environment Creation and Activities in Kindergartens [M]. Beijing: China Light Industry Press, 2013:3.

[7] Gao Guimei. On the Self-education of Preschool Teachers [J]. Educational Guide. 2011 (11): 56-59. 